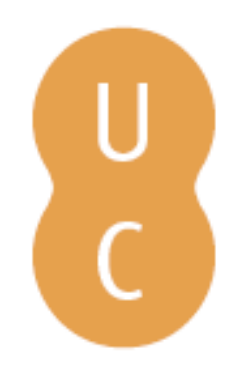

\title{
nommalina
}

\section{Conhecimento, afetividade e cuidado nos processos educativos em sociedades multiculturais}

\author{
Autor(es): $\quad$ André, João Maria \\ Publicado por: Imprensa da Universidade de Coimbra \\ URL \\ persistente: URI:http://hdl.handle.net/10316.2/43537 \\ DOI: $\quad$ DOI:https://doi.org/10.14195/978-989-26-1343-7_39 \\ Accessed : $\quad$ 26-Apr-2023 11:18:17
}

A navegação consulta e descarregamento dos títulos inseridos nas Bibliotecas Digitais UC Digitalis, UC Pombalina e UC Impactum, pressupõem a aceitação plena e sem reservas dos Termos e Condições de Uso destas Bibliotecas Digitais, disponíveis em https://digitalis.uc.pt/pt-pt/termos.

Conforme exposto nos referidos Termos e Condições de Uso, o descarregamento de títulos de acesso restrito requer uma licença válida de autorização devendo o utilizador aceder ao(s) documento(s) a partir de um endereço de IP da instituição detentora da supramencionada licença.

Ao utilizador é apenas permitido o descarregamento para uso pessoal, pelo que o emprego do(s) título(s) descarregado(s) para outro fim, designadamente comercial, carece de autorização do respetivo autor ou editor da obra.

Na medida em que todas as obras da UC Digitalis se encontram protegidas pelo Código do Direito de Autor e Direitos Conexos e demais legislação aplicável, toda a cópia, parcial ou total, deste documento, nos casos em que é legalmente admitida, deverá conter ou fazer-se acompanhar por este aviso.

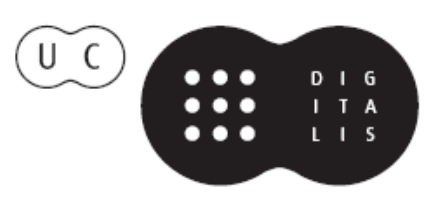




\section{FERNANDA CRAVIDÃO}

\section{IÚCIO CUNHA}

PAULA SANTANA

\section{NORBERTOSANTOS}

(ORG.)

\section{ESPAÇOS E TEMPOS EM GEOGRAFIA}

HOMENAGEM A ANTÓNIO GAMA

IMPRENISA DÁ UNIVERSIDADE DE COIMBRA COIMBRA UNIVERSITY PRESS

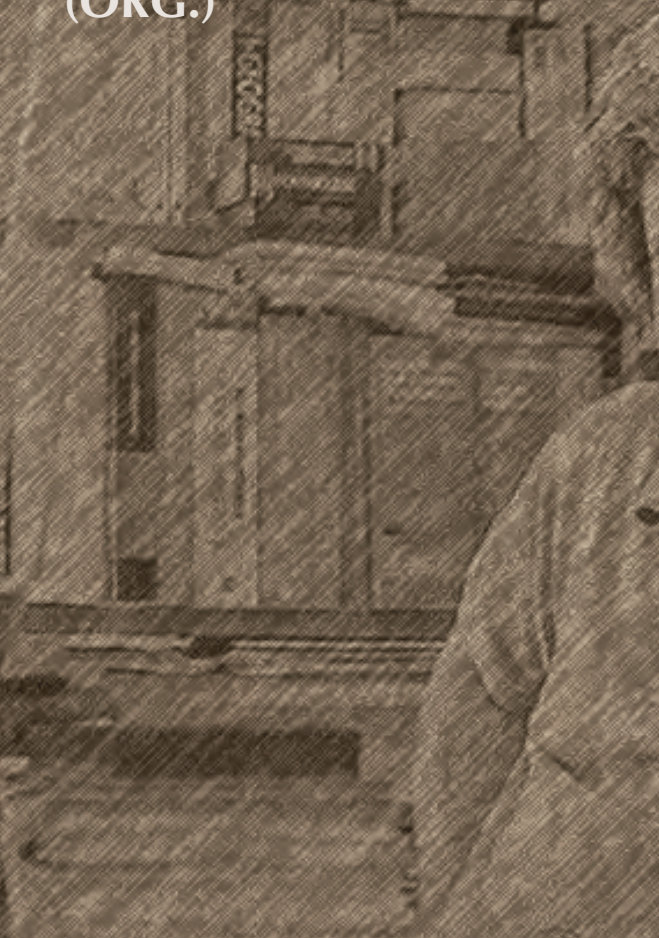




\section{CONHECIMENTO, AFETIVIDADE E CUIDADO NOS PROCESSOS EDUCATIVOS EM SOCIEDADES MULTICULTURAIS}

João Maria André/jmandre@sapo.pt. Faculdade de Letras da Universidade de Coimbra

\section{I - Introdução}

As sociedades contemporâneas são sociedades crescentemente marcadas pela intensificação da sua multiculturalidade. Entre os motores que mais potenciam essa multiculturalidade, destacam-se a globalização, por um lado, a sociedade em rede, por outro, e ainda os fluxos migratórios com as marcas específicas que têm assumido nos anos mais recentes. Desses fluxos migratórios adquirem agora especial importância as ondas de refugiados que procuram a Europa no quadro da desestruturação total das condiçóes de existência nos seus países de origem marcados pela guerra ou por conflitos étnicos e religiosos de diferente natureza. Se a globalização e a sociedade em rede pareciam conduzir a uma erosão progressiva da estrutura clássica dos Estados-Nação, a acentuação dos fluxos migratórios e, mais recentemente, dos movimentos de refugiados começa a criar mecanismos defensivos em nome do mesmo Estado-Nação em que o “outro" é visto como uma ameaça, colocando em causa as políticas de acolhimento assentes no diálogo intercultural que se vinham desenhando há alguns anos e questionando os modelos educativos que se articulavam com essas políticas. Neste contexto, parece-me 
importante repensar os processos educativos numa sociedade multicultural a partir das componentes antropológicas e éticas que os podem fundamentar na sua diferença relativamente à educação em sociedades monoculturais, já que a sociedade que hoje se define como uma sociedade do conhecimento náo pode deixar de se assumir, neste contexto e com base no que acabámos de referir, como uma sociedade marcada pela diversidade de culturas em proximidades física, geográfica e também virtual ${ }^{1}$.

Importa ter em conta que falar de encontros de culturas é, antes de mais, falar de encontros de povos, comunidades, grupos e pessoas. As culturas encontram-se através dos seus sujeitos e é neles e por eles que elas têm uma dimensão subjetiva ${ }^{2}$. O que significa que o diálogo intercultural não é apenas e só o encontro de ideias e teorias sobre o homem, o mundo, a natureza e a vida, mas também o encontro de pessoas concretas que têm rostos, memórias, nomes, sonhos e projetos, sendo assim no quadro também do encontro pessoal que tem de ser pensado o diálogo e que tem de ser pensada a educaçáo. Daí a proposta que aqui formulamos de uma complementaridade entre o conhecimento e a afetividade nos processos educativos em sociedades multiculturais.

\footnotetext{
${ }^{1}$ Lecionei com o colega e amigo António Gama uma cadeira do curso de Estudos Europeus designada Migrações e Multiculturalismo na Europa. As preocupaçôes com os temas da multiculturalidade alimentaram muitas das nossas conversas e estavam no centro dos nossos interesses. Este texto resulta do aprofundamento de uma comunicação que apresentei no Colóquio "Perfil ético do professor na sociedade do conhecimento", organizado na Faculdade de Psicologia e Ciências da Educação, no âmbito do projeto de doutoramento de Sónia Rodrigues, e com a colaboração dos Centros de Formação de Professores Nova Ágora e Minerva. Ao publicá-lo neste livro, exprimo a minha gratidão pelo muito que ao longo dos anos aprendi com o António Gama, que era também homem de diversificados conhecimentos e interesses e de grandes afetos.

2 Cf. M. Abdallah-Pretceille, Vers une pédagogie interculturelle, Paris, Anthropos, 2004, pp. 24-34.
} 


\section{II - Premissas antropológicas do exercício do ensino numa sociedade do conhecimento na tradiçáo da Modernidade e dos processos educativos em sociedades multiculturais}

Ao fazer a genealogia da atual sociedade do conhecimento nos seus pressupostos filosófico-antropológicos que acabam por a moldar em traços dominantes nas suas implicaçóes pedagógicas, parece-nos importante explicitar três premissas que acabam por ser determinantes para a configuração de alguns modelos ainda dominantes na esfera educativa das sociedades ocidentais.

A primeira dessas premissas diz respeito ao dualismo antropológico entre a dimensão física e corporal e a dimensão espiritual e mental do ser humano, que, no processo de constituição da Modernidade Ocidental tem a sua raiz na filosofia cartesiana que acaba por reinterpretar e reconfigurar o dualismo herdado da tradição platónica. A contraposiçáo entre a res cogitans e a res extensa, reduzindo, de alguma forma, o sujeito à res cogitans e objetivando, consequentemente, a partir de um pensamento sub specie machinae a res extensa, isto é, o corpo humano e, com ele, todo o mundo das coisas materiais ${ }^{3}$, desnaturaliza o homem e desumaniza a natureza, fazendo apenas da alma ou da mente o sujeito único do processo educativo, com a consequente subalternização da dimensão corpórea nesse mesmo processo.

A segunda premissa, decorrente da primeira, refere-se ao dualismo entre pensamento e afetividade ou entre razão e paixão, com uma clara desvalorização da afetividade, das emoçôes e das paixóes quer na arquitetura do comportamento humano quer na arquitetura do processo de construçáo do saber e do conhecimento (o método $)^{4}$. Privilegia-se, assim, a dimensão lógica do agir humano e a própria ciência é vista como o resultado de um processo em que os afetos

\footnotetext{
${ }^{3}$ Cf. Descartes, Meditationes, VI, in Euvres, (Ed. Adam et Tannery), VII, Paris, Vrin, 1996, pp. 71-90.

${ }^{4}$ Embora mais recentemente alguns intérpretes tenham vindo a resgatar a importância da afetividade no pensamento cartesiano, sobretudo a partir de As paixóes da Alma, náo deixa de se registar, mesmo assim, um acentuado dualismo entre o pensamento e a afetividade. Cf, a este propósito, João Maria André, Pensamento e afectividade, Coimbra, Quarteto, 1999, pp. 19-36.
} 
e as emoçóes devem ser suspensos ou colocados entre parêntesis em função de uma verdade dita pura, objetiva e desapaixonada, dando origem a uma razão indolente ou insensível tanto no que se refere aos conteúdos dos seus edifícios conceptuais, como no que se refere ao seu alcance e às suas implicaçôes ou aplicações mais práticas.

A terceira premissa prende-se com a aliança entre saber e poder, entre ciência e potência, transformando o sujeito do conhecimento num sujeito de domínio e o objeto do conhecimento, seja ele o mundo, os seres humanos, as circunstâncias ou a natureza, num objeto a dominar, bem patente quer no axioma de Bacon de que "a ciência e a potência humana coincidem" 5 , quer na palavra de ordem de Descartes, segundo a qual o objetivo da ciência é tornar-nos "como que mestres e senhores da natureza" ${ }^{6}$. Esta equivalência faz da previsibilidade (domínio antecipado dos acontecimentos) a condição para o exercício do poder: nestas circunstâncias, o tu deixa de ser uma pessoa inteira com a qual estou em relação, para ser mais um objeto na arquitetura da construção dominada dos acontecimentos do mundo. O progresso é assim visto como a perda da opacidade do mundo e a perda da opacidade do mundo é vista como a sua crescente previsibilidade e dominabilidade.

A estas três premissas contrapóem-se outras que devem suportar os processos educativos em sociedades multiculturais.

Em primeiro lugar, a premissa da unidade humana: corpo e alma, físico e espiritual não são duas coisas (duas substâncias no sentido cartesiano), mas dois registos ou, se quisermos, duas interfaces do ser humano no processo interativo da sua interioridade com a sua exterioridade: se Espinosa o estabeleceu ao unificar as duas substâncias de Descartes ${ }^{7}$ (o que explica que António Damásio,

\footnotetext{
5 Francis Bacon, Novum Organon, L. I, af. 3 (Francis Bacon, Neues Organon, lateinisch-deutsch, Darmstadt, Wissenschatliche Buchgesellschaft, p. 80).

${ }^{6}$ Descartes, Discours de la méthode, VI, in Oeuvres, ed. cit., VI, p. 62.

${ }^{7}$ Cf. Espinosa, Ethica, II, prop. 13 in Opera, Lateinisch-Deutsch, Darmstadt, Wissenschftliche Biuchgesellschaft, 1989, II, p. 180 e ss.
} 
depois de escrever $O$ erro de Descartes ${ }^{8}$ tenha escrito um outro livro, menos conhecido, intitulado À procura de Espinosa ${ }^{9}$ ), o médico-filósofo espanhol Pedro Laín Entralgo deixou-o muito claro quando, ao perguntar "o que é que eu sou?", responde lapidarmente que eu sou um corpo que diz eu: "Não 'o meu corpo e eu', mas 'o meu corpo: eu'. Não a auto-afirmação de um 'eu' para o qual algo de extremamente unido a ele, mas diferente dele, o corpo, fosse um servidor rebelde ou dócil _...- mas a auto-afirmação de um corpo que tem como possibilidade de dizer de si mesmo 'eu'" ${ }^{10}$. Decorre daqui, em termos educativos, que o ensino não deve ser visto apenas como uma transmissão de pensamentos mas como um encontro de eus na sua totalidade, ou seja, na sua dimensão cognitiva, mas também na sua dimensão física e corpórea, nos corpos que são todos os alunos, nos corpos que todos somos, alunos e professores. Numa sociedade multicultural as culturas circulam com as suas dimensóes materiais (os movimentos migratórios e as trocas comerciais numa sociedade global fazem circular corpos, vestuários, sons, línguas, músicas, sabores, objetos, artefactos, expressões artísticas, etc...) não havendo culturas sem pessoas e povos, que são grupos e comunidades de seres corpo-mente em movimento e em interação.

A segunda premissa dos processos educativos numa sociedade multicultural, decorrente da primeira, corresponde à indissociabilidade entre conhecimento e afetividade: o conhecimento é o conhecimento de um eu que, sendo um corpo que diz eu, o é de um corpo que sente, que toca e é tocado, que move, que se move e que se comove e, por isso, somos um pensamento que sente ao mesmo tempo que somos um corpo que pensa (pensamos sentindo e sentimos pensando), o que estabelece uma união incontornável entre conhecimento e

\footnotetext{
${ }^{8}$ Cf. António Damásio, O erro de Descartes, Mem Martins, Publicaçōes Europa-América, 1995.

${ }^{9}$ Cf. idem, À procura de Espinosa, Mem Martins, Publicaçôes Europa-América, 1995, 2003.

${ }^{10}$ Pedro Laín Entralgo, Corpo e Alma, trad. de M. S. Pereira, Coimbra, Almedina, 2003, p. 321. Cf., a propósito desta concepção de Laín Entralgo, Anselmo Borges, Corpo e transcendência, Coimbra, Almedina, 2011, pp. 72-76.
} 
afetividade $^{11}$. Por isso, o diálogo intercultural supóe não apenas a mobilização de dispositivos lógicos e conceptuais, mas também de dispositivos afetivos e emotivos, ou seja, supóe aquilo a que Raimon Panikkar chamou "o casamento sagrado (hieros gamos) entre o conhecimento e o amor" ao afirmar que "conhecimento sem amor é mero cálculo, não penetra no que conhece; amor sem conhecimento é simples emoção, não há identificação com o que se ama" 12 , concluindo daí que "qualquer aproximação sem amor a outra cultura é uma violação da outra cultura" e que "qualquer aproximação sem conhecimento é uma sedução mais ou menos imoral"13. A aproximação de outra cultura tem de ser, pois, uma aproximação entre a nossa subjetividade e a sua alteridade subjetiva e não apenas a sua dimensão objetiva. Assim, conclui o mesmo autor: "Sem a união entre o conhecimento e o amor a interculturalidade é uma palavra vazia. Sem interculturalidade, a paz é só uma utopia: o hieros gamos entre amor e conhecimento é uma esperança para a humanidade." 14

Finalmente, a terceira premissa dos processos educativos em sociedades multiculturais é a do exercício do conhecimento como entrada no mistério e na imprevisibilidade do mundo, da natureza, da realidade, das pessoas e dos povos numa perspetiva dialógica e não como condição de domínio objetivo do mundo, da natureza, da realidade, das pessoas e dos povos numa perspetiva planificadora e instrumental ${ }^{15}$, o que implica articular conhecimento com saber, saber com sabedoria e sabedoria com sabor: saborear não é a mesma coisa que mastigar ou engolir, é sentir, com todos os sentidos, o outro nos seus matizes, nas suas temperaturas, na sua beleza, na sua música, no seu aroma e na sua

${ }^{11}$ Cf., a este propósito, a distinção entre os três operadores do diálogo intercultural no campo das artes, em João Maria André, Multiculturalidade, Identidades e mestiçagem. O diálogo intercultural nas ideias, na política, nas artes e na religiäo, Coimbra, Palimage, 2012, pp. 153-157. Cfr. Ainda, do mesmo autor, "Oficinas interculturais de saber: um dispositivo para a educação intercultural", in Adalberto Dias de Carvalho (Org.), Interculturalidade, educação e encontro de pessoas e povos, Porto, Ediçôes Afrontamento, 2013, pp. 147-154.

12 Raimon Panikkar, Paz e interculturalidad. Una reflexión filosófica, Barcelona, Herder, 2006, p. 140 .

13 Idem, ibidem, p. 141.

${ }^{14}$ Idem, ibidem, p. 148.

15 Cf. Raimon Panikkar, Mito, Fe y Hermenéutica, Barcelona, Herder, 2007, pp. 43-59. 
suavidade ou na sua rudeza, ou seja, sentir com a vista, com os ouvidos, com o tato, com o cheiro e com o paladar, e sentir assim não é dominar, é apenas adentrar-se no mistério da alteridade.

\section{III - A vulnerabilidade como característica antropológica fundamental dos mais recentes processos de multiculturalidade}

Os mais recentes processos de intensificação da multiculturalidade nas sociedades atuais têm a ver com a migração económica, por um lado, e os fluxos e acolhimento de refugiados por outro. Tanto num caso como no outro, o que mais caracteriza a situação de origem das pessoas, famílias, grupos e povos em circulação é a precariedade no acesso aos bens essenciais nos seus territórios e nos seus países natais, motivada por situaçôes de crise económica ou por conflitos bélicos que desorganizam economias, sociedades e todas as estruturas comunitárias. Transferindo-se para outros países em que são acolhidos e em que se vão incorporar sob o ponto de vista humano, social, económico e político, o seu mundo e a sua situação existencial e social serão marcados por aquilo a que se poderá chamar uma situação de profunda vulnerabilidade. Isso transforma a vulnerabilidade numa das características antropológicas fundamentais a ter em conta nos processos sociais, económicos, políticos e educativos no interior das sociedades multiculturais e, por esse motivo, impóe-se a necessidade de esboçar o que poderíamos chamar uma antropologia da vulnerabilidade.

1. Nessa antropologia da vulnerabilidade, começaríamos por apresentar uma definição genérica e englobante: a vulnerabilidade é a exposição do ser humano ao que lhe é exterior, numa relação marcada pela assimetria. Como primeira nota desta definição há que assinalar que a base de uma antropologia da vulnerabilidade é a dimensão relacional do ser humano. Em segundo lugar, constata-se que a vulnerabilidade começa por significar uma relação assimétrica com o outro (há seres que estão numa situação de poder: poder fazer, poder ser, poder sorrir, poder falar, poder ser feliz e há seres que estão, nessa situação 
numa situação de debilitação desse mesmo poder ou desses mesmos poderes), o que significa que não havendo igualdade, nem reciprocidade, resulta daí uma relação de dependência; mas a vulnerabilidade significa ao mesmo tempo uma relação desfavorável com o mundo ou com o contexto: significa que o ser humano não tem capacidade para fazer face aos desafios do que o rodeia, seja o mundo social, seja o mundo físico ${ }^{16}$.

2. A partir desta definição, importa enumerar alguns traços mais característicos da situação antropológica de um ser vulnerável. Podemos enunciá-los em cinco alíneas.

Em primeiro lugar, a relação com o tu desestrutura-se em todas as dimensôes da vida humana e a existência humana fragiliza-se na sua dimensão dialógica, que é uma dimensão construída através da comunicação ${ }^{17}$.

Em segundo lugar verifica-se uma ameaça da identidade do ser vulnerável, ou seja, a construção do seu self em interação com o outro (a identidade é sempre uma identidade dialógica ${ }^{18}$ ) e, por isso, um ser vulnerável é sempre um ser cuja identidade está em vias de fragmentação ou de dissolução; mas se a identidade se constrói também na relação de cada um consigo próprio e, por isso, na narrativa de si próprio ${ }^{19}$, então, ao perder-se a interaçáo com o outro perde-se também a relação consigo próprio, o que é importante não só no que se refere à identidade pessoal, mas também nos contextos de multiculturalidade em que o que está em causa é a identidade sociocultural.

\footnotetext{
16 Sobre esta dupla relaçấo definidora da vulnerabilidade e do carácter assimétrico que a marca, cf. Marc-Henry Soulet, "La vulnérabilité: examen critique d'une notion", in Marc-Henry Soulet (éd.), Vulnérabilité: de la fragilité sociale à l'éthique de la sollicitude, Fribourg, Academi Press Fribourg, 2014, pp. 27-33.

${ }^{17}$ Cf. Martin Buber, Je et tu, trad. de G. Bianquis, Paris, Aubier-Montaigne, 1981. Cf. também Miguel Baptista Pereira, "Filosofia e crise actual de sentido", in M. B. Pereira et alii, Tradição e crise. I, Coimbra, Faculdade de Letras, 1986, pp. 5-167.

18 C. TAYLOR, "A política do reconhecimento", in Charles Taylor et alii, Multiculturalismo. Examinando a politica do reconhecimento ${ }_{s}$ trad. de M. Machado, Lisboa, Instituto Piaget, 1998, p. 54.

${ }^{19}$ Cf. Paul Ricoeur, Soi-même comme un autre, Paris, Seuil, 1990, pp. 167-180. Cf. também "L’identité narrative", in Paul Ricoeur, Anthropologie philosohique, Écrits et conférences 3, Paris Éditions Du Seuil, pp. 355-375.
} 
Em terceiro lugar, constata-se igualmente uma ameaça da gestão do tempo da existência: a vulnerabilidade desequilibra a relação com o passado, que ou se torna uma sombra desfocada ou se expande de tal modo que não deixa olhar nem para o presente nem para o futuro, fazendo viver um passado de tal modo expandido que não deixa espaço para a imersão no presente e transforma assim a angústia do tempo na angústia da saudade; mas desequilibra também a relação com o futuro porque a angústia do presente ou a saudade do passado bloqueiam a capacidade de se inventar e de se projetar para o futuro e a perda do futuro é também, ao mesmo tempo, a perda da esperança traduzindo-se assim, mais uma vez, na clausura do tempo. Mas a perda do futuro é também a perda da promessa e do projeto $^{20}$ : somos não só o que fomos, mas somos já, em certa medida, o que queremos ser e daí que a construçáo de um projeto de vida seja o primeiro cuidado que se tem com pessoas em situação vulnerável, como são os imigrantes ou os refugiados.

Em quarto lugar regista-se a ameaça da capacidade de sentir com o corpo, com a pele e com os gestos, ou seja, a ameaça da assunção da nossa própria corporalidade, pois é na aprendizagem do corpo que vamos fazendo a aprendizagem do que somos.

Por último, intensifica-se, em situaçôes de vulnerabilidade, a perda da voz e da palavra: é pela voz e pela palavra que a existência humana se projeta, em primeiro lugar, para os outros no campo simbólico que é a linguagem e, como sons emitidos pelo corpo e acolhidos pelo corpo, a voz e a palavra fazem parte do corpo que o homem é; mas a voz e a palavra são, além disso, a possibilidade de inscriçáo do simbólico, a abertura do espaço do sentido e o percurso pelos seus caminhos e pelas suas clareiras. Por isso, a privação da voz e da palavra é a privação de si e da capacidade de agir ${ }^{21}$, o que adquire uma especial importância em situaçôes e processos de intensificação da multiculturalidade através de fluxos de imigrantes e de refugiados. Aqui é particularmente importante dar

${ }^{20}$ Cf. Paul Ricoeur, "Projecto universal e multiplicidade de heranças", in J. Bindé ((Dir.), Para onde vão os valores?, Trad. de L. C. Feio, Lisboa Instituto Piaget, 2006, p. 74.

21 Cf. Guillaume le Blanc, Vies ordinaires, vies précaires, Paris, Éditions du Seuil, 2007, pp. 139-145 e 157-161. 
voz a quem está em vias ou em processo de a não ter, o que significa, antes de mais, ser capaz de escutar, de estimular o acontecimento do diálogo, de deixar que o outro fale e se exprima. Além disso, é necessário ter em conta que, sendo a presença do corpo, na palavra, também uma presença intensa, não basta deixar falar ou falar para romper a mudez, mas é preciso falar com o peso (as palavras também pesam) e escutar o peso das palavras, falar com calor (as palavras também aquecem) e escutar o calor das palavras, descobrir a intimidade da voz (a voz pode chegar onde o olhar náo chega, ao mais íntimo de uma pessoa) e despir as palavras do ruído que não deixa espaço para o pensamento, para o acolhimento sereno, para o desatar da voz embargada do outro nos soluços da sua vulnerabilidade. Por esse motivo, todos os professores deveriam ter uma especial atenção a este aspeto e muito mais aqueles que trabalham no quadro de uma educação intercultural.

3. Emergem, assim, quatro dimensóes fundamentais da vulnerabilidade a que correspondem algumas vertentes axiais mas complementares na resposta que lhes é dada.

A primeira é a que poderíamos designar dimensão biológico-natural: tem a ver com elementos factuais inerentes a uma determinada situação da pessoa vulnerável, quer em termos do sua constituição biológica e respetiva transformação, quer na sua relação com a natureza em que se insere, ganhando especial relevância no contexto de uma sociedade de risco cuja estabilidade se vê ameaçada por catástrofes que interferem com o nosso enraizamento físico e biológico.

A segunda dimensão é o que se poderia considerar, em sentido próprio e específico, a dimensão existencial humana marcada pela consciência da finitude da pessoa vulnerável: uma antropologia da vulnerabilidade é sempre uma antropologia da finitude no sentido de uma antropologia da consciência da finitude.

A terceira dimensão é, em termos mais diretos, a sua dimensão social, relacionada com o enquadramento social que a potencializa ou que potencializa a situação de vulnerabilidade e que se prende com o cruzamento do 
económico, do político e do social com o sentido existencial da consciência da finitude ${ }^{22}$.

Finalmente, acrescentaria às três dimensóes anteriores a sua dimensão cognitiva ou conceptual, marcada pelo jogo do conhecimento e do desconhecimento dos fatores que potencializam as situaçóes de vulnerabilidade e que questionam as certezas inerentes ao exercício do conhecimento como previsibilidade e domínio: os acontecimentos que provocam a vulnerabilidade acentuam a fragilidade do conhecimento humano numa sociedade da incerteza como é também aquela em que vivemos e que se repercute numa fragilidade do mundo tal como o conhecemos, sendo a intensificação recente do fenómeno dos refugiados e as respostas contraditórias que lhe são dadas um índice claro desta dimensão, já que a sociedade europeia e a civilização ocidental sentiu, de repente, toda a sua vulnerabilidade na dificuldade em dominar conceptualmente um processo que ultrapassa muitas previsóes políticas à escala internacional.

Face a estas dimensôes e às notas resultantes de uma antropologia da vulnerabilidade, que implicam um entrelaçamento intenso entre conhecimento e afetividade, emerge um triplo eixo que deve comandar a intervenção em situaçóes de vulnerabilidade: $1 .^{\circ}$ por um lado esse eixo reclama uma atenção ao outro que se reflete no conceito de cuidado; $2{ }^{\circ}$ por outro, esse eixo inflete-se para a vertente centrada na capacidade de agir do ser vulnerável, na sua preservaçáo e potenciação (que tem a ver com a sua interioridade, mas que também tem a ver com a sua exterioridade); $3 .^{\circ}$ por outro lado ainda, o mesmo eixo inflete-se também para a vertente centrada na capacidade de autonomia (ou seja, agir de uma forma autónoma, isto é, de uma forma livre, o que implica a reconquista da liberdade). É ao pensamento desses eixos de intervenção que dedicaremos os próximos parágrafos.

\footnotetext{
22 Para a articulação da dimensão existencial e da dimensão social da vulnerabilidade com o seu sentido humano, cf. Danilo Martucelli, "Vulnérabilité exitentielle et vulnérabilité sociale", in Marc-Henry Soulet (éd.), op. Cit., pp. 40-45.
} 


\section{IV - O cuidado como resposta ética a situaçóes antropológicas marcadas pela vulnerabilidade}

Ao cuidado e à ética do cuidado começou por dar voz, nos anos 80, Carol Gilligan $^{23}$, ainda numa vinculação a um feminismo demasiado essencialista e a que outras autoras, como Joan Tronto ${ }^{24}$ e, entre nós, Maria de Lurdes Pintasilgo 25 , vieram a precisar posteriormente os contornos de uma forma mais alargada. Poderia radicar-se filosoficamente a sua fundamentação no capítulo vi de Ser e tempo, onde Heidegger define o cuidado como ser do Dasein, depois de apresentar a fábula 220 de Higino que coloca nas mãos do cuidado a modelação do homem a partir do húmus ${ }^{26}$ e encontrar outras bases para o seu desenvolvimento quer na Filosofia de Levinas do ser como bondade ${ }^{27}$, quer na forma como Paul Ricoeur aprofunda a natureza da solicitude em Soi-même comme un autre 28 .

1. Para a caracterização do que se entende por cuidado Joan Tronto retoma a proposta de Berenice Fischer, que define o cuidado nestes termos: "uma atividade genérica que compreende tudo o que fazemos para manter, perpetuar e reparar o nosso 'mundo', de modo que possamos aí viver tão bem quanto possível. Este mundo compreende os nossos corpos, nós próprios e o que nos rodeia, elementos que no seu conjunto procuramos religar numa

23 Cf. Carol Gilligan, Une voix différente. Pour une éthique du care, Paris, Flammarion, 2008, tradução de Annick Kwiatek da obra publicada originalmente com o título, In a different voice: Psychological Theory and Women's Development, pela Harvard University Press em 1982.

24 Cf. Joan Tronto, Un monde vulnérable. Pour une politique du care, texto publicado com o título Moral Boundaries, A political Argument for an Ethic of Care, em New York, pela Routledge, em 1993.

25 Cf, por exemplo, Maria de Lurdes Pintasilgo, "Cuidar o futuro", in Maria de Lurdes Pintasilgo, Para um novo paradigma: um mundo assente no cuidado, Porto, Ediçóes Afrontamento, 2012, pp. 127-138.

26 Cf. M. Heidegger, Sein und Zeit, Tübingen, Max Niemeyer Verlag, 19 Auf, 2006, $\$ 42$, pp. 197-198.

27 Cf., por exemplo, E. Levinas, Totalidade e infinito, trad. de J. P. Ribeiro, Lisboa, Ediçôes 70, 1988, pp. 284-287.

28 Cf. Paul Ricoeur, Soi-même comme un autre, pp. 254-264. 
rede complexa, como suporte da vida" ${ }^{29}$. Note-se como o cuidado diz tanto respeito aos outros, quanto ao ambiente e a tudo o que se prende com uma vida e uma vida boa e, se está presente na vida quotidiana, deve estar intensamente presente nos processos educativos.

Esta ética do cuidado afirma-se como complementar de uma ética da justiça, mas realiza dimensóes que essa ética da justiça náo chega a equacionar na sua radicalidade, ao partir mais da prática e de situaçóes concretas do que de conceitos abstratos e de princípios teóricos da igualdade e ao tomar como referência a vulnerabilidade que, em última análise, constitui um questionamento de universalidade e da igualdade: a vulnerabilidade mostra que todos os seres são diferentes e que os seres mais vulneráveis são marcados por uma diferença radical, não bastando invocar tudo o que de justo a que como seres humanos têm direito, mas acentuar que como seres vulneráveis têm decerto mais direitos que os direitos que têm os que são menos vulneráveis ${ }^{30}$. Assim, e no quadro em que agora nos movimentamos, a vulnerabilidade de estudantes de culturas minoritárias numa sociedade de acolhimento exige, como prolongamento do investimento afetivo, um comportamento marcado pelo imperativo do cuidado, um novo imperativo que complementa outros imperativos como, por exemplo, o imperativo categórico kantiano e que poderia ser formulado nestes termos: "Ser moralmente bom exige que se responda aos desafios do cuidado com os quais se é confrontado na vida."31

Da análise que faz Joan Tronto ao processo do cuidado, podemos retirar os seguintes elementos que ganham pleno sentido e alcance na relação pedagógica e no processo de ensino/aprendizagem: em primeiro lugar a atenção (caring about); em segundo lugar, a responsabilidade, que corresponde à capacidade de tomar a seu cargo o que é vulnerável, de responder por ele (taking care of); em terceiro lugar, a competência para responder de modo adequado ao cuidado de que o outro necessita, ou seja de lhe dar os cuidados respetivos (care-giving);

\footnotetext{
29 Joan Tronto, op. cit., p. 143.

30 Cf. Sandra Laugier, "Présentation” de C. Gilligan, op. cit., p. Ix.

31 Joan Tronto, op. cit, p. 172.
} 
finalmente, a capacidade de resposta do beneficiário (care-receiving), que se traduz numa aceitaçáo e no acolhimento daquele que com ele se preocupa ${ }^{32}$.

2. Mas face a fenómenos migratórios e às formas de atuaçáo com pessoas pertencentes a culturas minoritárias, nomeadamente no quadro da educação e, mais especificamente, da educação intercultural, parece-me importante prolongar e completar uma ética do cuidado com o que, no quadro das propostas de Amartya Sen ${ }^{33}$ e de Martha Nussbaum, se poderia designar uma ética e uma política das capabilidades ${ }^{34}$, tendo em conta a necessidade de pensar uma educação para a potenciação, para o empowerment e para a autonomia, pois a educação intercultural não é apenas uma transmissão de conhecimento mas uma capacitaçáo para a vida plena e, daí, o seu significado e o seu alcance político ${ }^{35}$.

No seu livro sobre as capabilidades, publicado em $2011^{36}$, a pensadora norte-americana caracteriza o quadro das capabilidades como uma perspetiva mais adequada para responder às questóes suscitadas pela existência de pessoas marcadas pela fragilidade, pela precariedade e pela exclusão. Efetivamente, na medida em que nessa perspetiva se faz uma aproximação de cada pessoa como um fim, opera-se uma concentração, na definição da ação, sobre a escolha ou a liberdade, sendo tal aproximação resolutamente pluralista na questão dos valores

32 Cf. idem, ibidem, pp. 173-183.

33 Cf. Amartya Sen, Inequality Reexamined, New York/Cambridge, Russel Sage/Harvard University Press, 1992.

${ }^{34}$ Mantemos a traduçáo literal, apesar da sua sonoridade estranha, por nos parecer que nem o conceito de capacidade, nem o conceito de possibilidade traduzem integralmente a noçấo de capabilidade que, se supōe capacidades internas e pessoais, exprime-as na sua indissociabilidade e na sua articulação com as condiçōes externas sociopolíticas que tornam possível o seu desenvolvimento, ou seja a noção de capabilidade remete para as possibilidades reais de desenvolvimento das suas capacidades.

35 Também Paul Ricoeur traça uma articulação entre as capacidades e o seu reconhecimento em "Capacités personelles et reconnaissance mutuelle", in Paul Ricoeur, Anthropologie philosohique, pp. $445-451$.

36 Cf. Martha Nussbaulm, Capabilités. Comment créer les conditions d'un monde plus juste?, trad. de Solange Chavel, Paris, Flammarion, 2012. 
e visando a correção das injustiças e das desigualdades sociais, o que constitui uma tarefa urgente para o governo e para as políticas públicas.

Definindo as capabilidades como "um conjunto de possibilidades (frequentemente interdependentes) de escolher e de agir" 37 , podemos vê-las como figuras ou formas da liberdade para atingir diferentes modos de realização, resultando da combinação de capacidades pessoais e de espaços, margens ou disposiçóes abertas pelo contexto político, social e económico que permite concretizá-las. A base antropológica de uma ética e de uma política das capabilbidades é, assim, a conceção da existência humana como projeto e como relação, ou seja, como poder ou possibilidade em interação.

Entre outras, Martha Nussbaum enumera algumas capabilidades centrais: a vida, a saúde do corpo e a sua integridade, os sentidos, a imaginaçáo e o pensamento, as emoçóes, a razão prática, a afiliaçáo, o relacionamento com as outras espécies e com o mundo natural, o jogo e a participaçáo na construçáo do seu meio-ambiente, quer político, quer material ${ }^{38}$.

Todas estas capabilidades mereceriam um aprofundamento e uma explicitação no contexto da educação intercultural e do trabalho com imigrantes e refugiados, não dispondo, por ora, de tempo nem de espaço para o fazer. No entanto, parece-me importante acrescentar a estas capabilidades centrais de que fala a autora a da voz e da palavra. Porque a perda ou a incapacidade da voz, como refere Guillaume le Blanc, "não pode senão gerar uma extinção das variaçóes do si e da própria capacidade de agir" ${ }^{39}$. Uma ética e uma política das capabilidades deve, assim, cuidar de dar voz e palavra a quem delas se vê privado, pois a devolução da voz é a devolução da face não sendo essa face visível, se a própria voz náo for audível ${ }^{40}$. Mas a capacidade da voz e da palavra é correlativa da capacidade da escuta: a escuta permite que estudantes vulneráveis se exprimam, se digam e se sintam ouvidos. Mas

\footnotetext{
37 Idem, ibidem, p. 39.

38 Cf. idem, ibidem, pp. 35-70.

39 Guillaume Le Blanc, op. cit., p. 223.

${ }^{40}$ Cf. idem, ibidem, p. 235.
} 
quando falamos aqui de escuta, devemos entender esta atitude ou esta virtude, se me é permitido falar assim, num sentido abrangente que ultrapassa a comunicação verbal: a escuta não é apenas a escuta da voz e da palavra, é também a escuta do corpo e dos gestos ${ }^{41}$. A escuta possibilita a instauração de um espaço social partilhado na relação de cuidado ${ }^{42}$, criando assim laços comunitários em quem eles se poderão ter rompido ou dissolvido. $\mathrm{Na}$ escuta irrompe a narração que desenha o "teatro da história" pessoal, com as suas ruturas, com as antecipaçóes de futuro e com as dinâmicas de repossibilitação da pessoa vulnerabilizada ${ }^{43}$.

\section{$\mathrm{V}-\mathrm{O}$ jogo do estranhamento e da familiarização}

Para completar a forma como conhecimento, afetividade e cuidado se jogam nos processos da educaçáo intercultural gostaria de me debruçar sobre o jogo aí implicado entre a "nossa cultura" e a "cultura dos outros", jogo esse que é caracterizado por dois processos distintos e interligados.

O primeiro desses processos é o processo da familiarização com aqueles que nos são estranhos ou estrangeiros e que se traduz no desenvolvimento de uma capacidade de compreensão a que Daniel Innerarity, na sua Ética da Hospitalidade, chama xenologia, que implica a experiência e a aproximação do que é estranho, sem o reduzir na sua alteridade, mas aprendendo-o e apreendendo-o nessa mesma alteridade ${ }^{44}$. O segundo processo é o processo do estranhamento de si em relaçáo a si próprio, ou seja a capacidade de se

${ }^{41}$ Cf. Lazare Benaroyo, "Éthique et herméneutique du soin ", in Lazare Benaroyo et alii (dir,), La philosophie du soin. Éthique, médecine et société, Paris, PUF, 2010, p. 29.

42 Cf. Catherine Draperi, "Narration, soin et accompagnement : accéder au monde de l'autre, in Lazare Benaroyo et alii, (dir.), op. cit., p. 39.

43 Idem, ibidem, p. 54.

44 Cf. Daniel Innerarity, Ética de la hospitalidad, Barcelona, Península, 2008, pp. 195-219. Ao tema do "estrangeiro" e à hospitalidade dedicou Derrida também especial atenção. Cf., por exemplo, Anne Dufourmontelle e Jacques Derrida, Da hospitalidade, trad. de Fernanda Bernardo, Coimbra, Pallimage, 2003. 
distanciar do que nos é mais próximo e familiar para o ver de fora, como estranho, e, assim, ser capaz de uma autocrítica das suas/nossas limitaçóes e de uma tentativa de superaçáo dessas mesmas limitaçôes. Trata-se da transposiçáo do processo de Verfremdung, que Brecht tematizou e operacionalizou como recurso no seu teatro épico e didático para o desenvolvimento da consciência crítica no contexto das artes ${ }^{45}$.

Estes dois processos cruzam-se e condicionam-se mutuamente na realização do diálogo e da aprendizagem intercultural das culturas e dos saberes. Mas, ao mesmo tempo, estes dois processos entrelaçam, na sua concretização, o conhecimento com a afetividade: a familiarização, para se traduzir numa xenofilia, tem de ser simultaneamente ao nível do logos e ao nível do eros (é preciso olhar afetivamente o outro para o conhecer e para conhecer a sua cultura), tal como o processo de estranhamento, para se traduzir numa abertura crítica à complementaridade do outro, tem de acontecer igualmente ao nível do eros (implicando, neste caso, uma espécie de desidentificação afetiva com o que nos é mais próximo) e ao nível do logos (através de um aprofundamento dos pressupostos e das implicaçôes de natureza teórica em que assenta a cultura que bebemos muitas vezes inconsciente e praticamos de forma também inconsciente no nosso quotidiano).

\section{VI - Do jogo entre o conhecimento e a afetividade à articulação entre uma pedagogia estética do sentido e da interpretaçáo e uma pedagogia estética da presença e da emoção}

Aproveitaria esta referência a categorias teatrais para concluir com uma outra aproximação que me parece extremamente pertinente neste quadro.

A história do teatro ocidental é fundamentalmente uma história do primado do texto e da interpretação dos seus sentidos, praticamente até ao final

45 Cf., por exemplo, Bertolt Brecht, Petit organon pour le théatre, trad. de Jean Tailleur, Paris, L'Arche, 2008, \$\$ 42-49, pp. 40-46. 
do século XIX (com algumas exceçôes nos primórdios do teatro grego ou no tempo da Commedia dell'arte). No teatro de outras culturas, nomeadamente afro-asiáticas e sul-americanas e no teatro ocidental sobretudo a partir do início do século $\mathrm{xx}$, esse primado do texto e do sentido foi progressivamente deslocado da sua posiçáo central pela entrada em cena da emergência do corpo e de uma estética da presença, que mais do que preocupada com os signos textuais, se afirma pela força emotiva do corpo na sua capacidade de interpelar e desencadear emoções ${ }^{46}$ e que Hans Gumbrecht traduziu no conceito de produção de presença ${ }^{47}$, em convergência, aliás, com o ensaio contra a interpretação de Susan Sontag ${ }^{48}$.

É sabido, desde as pertinentes análises de E. Goffman, que quotidianamente encenamos as nossas representaçóes no mundo e com os outros ${ }^{49}$ e sabemos também que a relação pedagógica é, em certo sentido, um espaço privilegiado para esse teatro da representação. Mas o que é importante é que se perceba que nessa representaçáo não basta estar atento a uma estética do sentido (relacionada com a dimensáo cognitiva da aprendizagem e articulada com o teatro do primado do texto) mas também a uma estética da presença (relacionada com a dimensão afetiva e emotiva da relação pedagógica), mormente em situaçóes de multiculturalidade, em que a par de uma semântica da cultura, é indispensável realçar a importância de uma somática da cultura ${ }^{50}$, pois a aprendizagem cultural passa também pelo corpo, pelas emoçóes e pelos afetos. Daí que a consciência do corpo como forma de produção de presença e como vetor semântico deva merecer uma atenção que não tem merecido suficientemente nos processos educativos. Se um professor souber como é que uma cultura se afirma pelo corpo, produz corporalmente a sua presença e exprime corporalmente os seus

46 Cf. Marco de Marinis, Il teatro dell'altro, Firenze, Sansoni, 2012, esp. pp. 201-204.

47 Cf. H. U. Gumbrecht, Produção da presença ou o que o sentido não consegue transmitir, trad. de A. I. Soares, Rio de Janeiro, PUC-Rio, 2010.

48 Cf. Susan Sontag, "Contra a interpretaçâo", in Susan Sontag, Contra a interpretação e outros ensaios, trad. de J. Lima, Lisboa, Gótica, 2004, pp. 19-32.

${ }^{49}$ Cf. E. Gofffman, A apresentação do eu na vida de todos os dias, trad. de M. S. Pereira, Lisboa, Relógio d'Água, 1993.

${ }^{50}$ Cf. João Maria André, Multiculturalidade, Identidades e Mestiçagem, pp. 143-209. 
sentidos e, ao mesmo tempo, tiver consciência de que os seus gestos, o seu modo de estar e o seu modo de comunicar são também marcados corporalmente, conseguirá superar obstáculos à comunicaçáo intercultural e abrir espaços de diálogo e de partilha naquelas margens em que a palavra revela os seus limites e o corpo manifesta o seu poder.

Paradela da Cortiça, Janeiro de 2016 